\title{
Spine radiographs to improve the identification of women at high risk for fractures
}

\author{
J. C. Netelenbos • W. F. Lems • P. P. Geusens • \\ H. J. Verhaar • A. J. M. Boermans • M. M. Boomsma • \\ P. G. H. Mulder $\cdot$ S. E. Papapoulos
}

Received: 2 January 2008 / Accepted: 15 October 2008/Published online: 28 November 2008

(C) International Osteoporosis Foundation and National Osteoporosis Foundation 2008

\begin{abstract}
Summary In women older than 60 years with clinical risk factors for osteoporosis but without osteoporosis based on bone mineral density ( $T$-score $\geq-2.5$ ), a systematic survey with X-rays of the spine identified previously unknown vertebral deformities in $21 \%$ of women.

Introduction This study determines the prevalence of vertebral deformities in elderly women with clinical risk factors for osteoporosis but with BMD values above the threshold for osteoporosis ( $T$-score $\geq-2.5$ ).

Methods Bisphosphonate naïve women older than 60 years attending 35 general practices in the Netherlands with $\geq 2$ clinical risk factors for osteoporosis were invited for BMD measurement (DXA). In women with $T$-score $\geq-2.5$ at both
\end{abstract}

J. C. Netelenbos $(\bowtie)$

Department of Endocrinology,

VU University Medical Center,

De Boelelaan 1117,

1081 HV Amsterdam, The Netherlands

e-mail: c.netelen@vumc.nl

W. F. Lems

Department of Rheumatology,

VU University Medical Center,

Amsterdam, The Netherlands

P. P. Geusens

Department of Internal Medicine/Rheumatology,

University Hospital,

Maastricht, The Netherlands

P. P. Geusens

University Hasselt,

Hasselt, Belgium spine and the hips, lateral radiographs of the thoracic and lumbar spine were performed.

Results Of 631 women with a DXA measurement, 187 (30\%) had osteoporosis ( $T$-score $<-2.5$ at the spine or the hip). Of the remaining 444 women with $T$-score $\geq-2.5$ at both spine and hip, 387 had additional spine radiographs, of whom $80(21 \%)$ had at least one vertebral deformity.

Conclusion In elderly women with clinical risk factors for osteoporosis but BMD $T$-score $\geq-2.5$, addition of spine radiographs identified vertebral deformities in $21 \%$ (95\% CI: 17-25). Since these women are at risk of future fractures, antiosteoporotic treatment should be considered.

\section{H. J. Verhaar}

Mobility Laboratory, Department of Geriatric Medicine,

University Medical Center,

Utrecht, The Netherlands

\section{A. J. M. Boermans}

Lutterstraat 2a,

NL-7581 BV Losser, The Netherlands

M. M. Boomsma

Medical department, GlaxoSmithKline,

Zeist, The Netherlands

P. G. H. Mulder

Erasmus University Medical Center,

Rotterdam, The Netherlands

S. E. Papapoulos

Department of Endocrinology and Metabolic Diseases,

University Medical Center,

Leiden, The Netherlands 
Keywords Bone mineral density . Case finding .

Dual-energy X-ray absorptiometry · Spine radiographs

\section{Introduction}

Primary osteoporosis is a chronic, progressive, and agerelated bone disease. It is characterized by low bone mass and structural deterioration of bone tissue which causes bones to become more fragile over time, increasing their susceptibility to fracture. Approximately $55 \%$ of individuals 50 years of age and over are at risk or may have evidence of osteoporosis [1, 2]. Although osteoporosis itself is a silent disease, its long-term clinical consequences, the occurrence of fractures, have a significant impact on quality of life, morbidity, and mortality. In the Netherlands, the prevalence of osteoporosis in women of 55 years and older is estimated at 166 per 1,000 giving a total estimate of 344,200 women while the prevalence of severe vertebral deformities is 237 per 1,000 women of 55 years and older giving a total estimate of 237,000 women [3, 4].

Identification of patients at risk for osteoporotic fractures and subsequent treatment is generally based on assessment of clinical risk factors followed by measurements of bone mineral density (BMD) by dual-energy X-ray absorptiometry (DXA) [5]. Spine radiographs are not recommended in current guidelines of fracture risk assessment despite the importance of vertebral deformities as an independent risk factor for fractures and the success of therapeutic interventions in individuals with prevalent vertebral fractures. However, results from the European Prospective Osteoporosis Study underlined the importance of spine radiographs in the estimation of risk-based algorithms for fracture prediction [6].

In the present study, we assessed the prevalence of vertebral deformities in elderly women with clinical risk factors for fractures but without osteoporosis according to bone mineral density measurements.

\section{Materials and methods}

The study was conducted in 35 primary care centers in the Netherlands among women $\geq 60$ years.

Women without a registered diagnosis of osteoporosis who had never received bisphosphonate treatment were evaluated for the presence of clinical risk factors for fractures. For every woman, a risk factor score was calculated as recommended by the national guideline that included 'Early menopause' and 'Moderate dose of corticosteroids' as additional risk factors (Table 1). The risk factors have been assessed by Evidence Based Medicine criteria and were published in the monograph "Osteoporose; tweede herziene richtlijn" (Osteoporosis; second revised guideline) which includes also a full cost-effectiveness analysis and is distributed to all Dutch physicians [7]. Women with a risk score $\geq 2$ were invited for a BMD measurement by DXA. Information about the total number of screened women who did not accept BMD measurements was not obtained. BMD measurements were performed in normal clinical practice at the lumbar spine L2-4 anteroposterior view and the total hip. Since this was a multicenter study, different DXA machines were used. $T$-scores were determined according to references provided by the manufacturers. Calibration was performed on a daily basis. If a woman accepted BMD measurement and if the DXA result was not diagnostic of osteoporosis ( $T$ score $\geq-2.5$ at both spine and the hips) radiographs of the thoracic and the lumbar spine were performed (lateral and anteroposterior). All radiographs were examined centrally for the presence of vertebral deformities by a radiologist who was unaware of the patients' risk scores by the semiquantitative method of Genant [8].

\section{Results}

A total of 660 women with risk scores $\geq 2$ were enrolled into the study across 35 centers in the Netherlands. Twenty nine withdrew from the study and did not have a DXAscan. The remaining 631 women agreed to have a DXAscan and of those 187 (30\%; 95\% CI: 26-33) had osteoporosis ( $T$-score $<-2.5$ at the spine and/or at the hip). Of the 444 women with $T$-scores $\geq-2.5$ at both spine and the hips, 387 agreed to have an additional $\mathrm{x}$-ray, and 57 women did not agree. These 57 women were slightly younger (68 versus 71 years; $p<0.0005$ ), and more often were menopausal before the age of 45 (54\% versus $31 \%$; $p=0.005)$. Six patients had an X-ray unsuitable for

Table 1 Extended risk factor analysis based on CBO Osteoporosis guideline 2002 [5]

\begin{tabular}{|c|c|}
\hline Risk factors & Score \\
\hline Fracture after age of 50 years ${ }^{\mathrm{a}}$ & 2 \\
\hline Existing vertebra fracture & 2 \\
\hline Low body weight $(<67 \mathrm{~kg})$ & 1 \\
\hline Current serious immobilization ${ }^{\mathrm{b}}$ & 1 \\
\hline $\begin{array}{l}\text { Positive familial history for fragility fractures } \\
\text { (particularly hip fracture in mother) }^{\mathrm{a}}\end{array}$ & 1 \\
\hline Early menopause (before age of 45 ) & 1 \\
\hline $\begin{array}{l}\text { Current use of corticosteroids for at least } 3 \text { months } \\
\text { ( } \geq 7.5 \mathrm{mg} \text { prednisone (equivalent) daily) }\end{array}$ & 2 \\
\hline $\begin{array}{l}\text { Current use of corticosteroids for at least } 3 \text { months } \\
\text { ( } \leq 7.5 \mathrm{mg} \text { and } \geq 2.5 \mathrm{mg} \text { prednisone (equivalent) daily) }\end{array}$ & 1 \\
\hline Total risk score & \\
\hline
\end{tabular}

\footnotetext{
${ }^{\text {a }}$ Rating based upon clinical judgment

${ }^{\mathrm{b}}$ Not walking for $\geq 4$ weeks in the last year
} 
Fig. $1 D X A+T$-score $<-2.5$, $D X A-T$-score $\geq-2.5, X$-ray + vertebral fracture present, $X$-ray - no vertebral fracture present

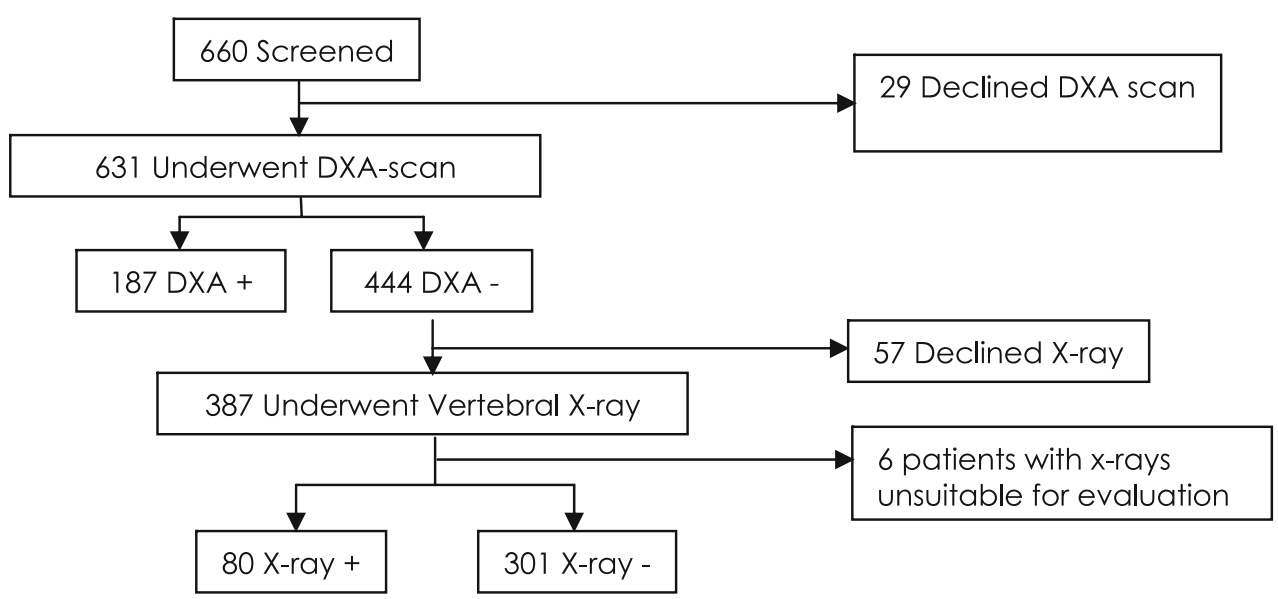

evaluation and were excluded. Eighty out of 381 women (21\%; 95\% CI: 17-25) had at least one vertebral deformity on spine radiographs (Fig. 1). However, it should be noted that $19(24 \%)$ of these patients were already known with vertebral fractures, but no therapeutic action had been undertaken. Excluding all patients with known vertebral fractures, $61(17 \%)$ out of 358 patients with a BMD score $T \geq 2.5$ had vertebral fractures. Patient characteristics are listed in Tables 2 and 3. So, in the current study, 574 women followed the full case-finding protocol (631 minus 57 women who refused to undergo an X-ray). A total of 267 women qualified for osteoporosis (187 women with a BMD $T<2.5$ plus 80 women with vertebral fractures on X-ray). With this case-finding strategy, 47\% (267/574) of the selected women (risk factors for osteoporosis and age 60 years or older) who followed all steps of the protocol qualified for osteoporosis treatment according to the guideline.

\section{Discussion}

Epidemiological studies have demonstrated that a significant number of individuals with incident osteoporotic fractures have BMD values above the WHO diagnostic threshold of osteoporosis ( $T$-score $\geq-2.5$ ) [9-12]. Findings of a recent study indicate that at any given BMD $T$-score, the risk of incident vertebral, non-vertebral, and any fracture depended heavily on prevalent radiographic vertebral fracture status. For any given BMD T-score, the risk of an incident vertebral, non-vertebral fragility, and any fracture differs by up to twelve times, two times, and seven

Table 2 Patient demographics at baseline

\begin{tabular}{|c|c|c|}
\hline & $\begin{array}{l}\text { Women with a DXA-scan } \\
N=631\end{array}$ & $\begin{array}{l}\text { Women with an X-ray } \\
N=381^{\text {a }}\end{array}$ \\
\hline Age mean [range] & $71[59-94]$ & $71[59-94]$ \\
\hline Height mean [range] & $162[137-185]$ & $163[146-185]$ \\
\hline Weight mean [range] & $69[40-120]$ & $70[46-120]$ \\
\hline Race (Caucasian/ oriental/other) & $99.1 / 0.6 / 0.3$ & $99.2 / 0.5 / 0.3$ \\
\hline Fracture after age of 50 years $\mathrm{s}^{\mathrm{b}}$ & $70 \%$ & $70 \%$ \\
\hline Known existing vertebral fracture & $7 \%$ & $6 \%$ \\
\hline Low body weight $(<67 \mathrm{~kg})$ & $46 \%$ & $41 \%$ \\
\hline Low body weight $(<60 \mathrm{~kg})$ & $25 \%$ & $20 \%$ \\
\hline Current serious immobilization $^{\mathrm{a}}$ & $15 \%$ & $14 \%$ \\
\hline $\begin{array}{l}\text { Positive familial history for fragility fractures } \\
\text { (particularly hip fracture in mother) }\end{array}$ & $2 \%$ & $1 \%$ \\
\hline Early menopause (before age 45 ) & $31 \%$ & $31 \%$ \\
\hline $\begin{array}{l}\text { Current use of corticosteroid } \geq 3 \text { months }(<7.5 \mathrm{mg} \\
\text { and } \geq 2.5 \mathrm{mg} \text { prednisone (equivalent) daily) }\end{array}$ & $31 \%$ & $34 \%$ \\
\hline $\begin{array}{l}\text { Current use of corticosteroids } \geq 3 \text { months }(\geq 7.5 \mathrm{mg} \\
\text { prednisone (equivalent) daily) }\end{array}$ & $2 \%$ & $2 \%$ \\
\hline
\end{tabular}

Six patients with X-ray unsuitable for evaluation not included

${ }^{\text {a }}$ Not walking for $>4$ weeks in the last year

${ }^{\mathrm{b}}$ Rating based upon clinical judgment 
Table 3 Patient demographics according to DXA and X-ray outcome

\begin{tabular}{|c|c|c|c|c|}
\hline & $\begin{array}{l}\text { DXA positive } \\
N=187\end{array}$ & $\begin{array}{l}\text { DXA negative } \\
N=444\end{array}$ & $\begin{array}{l}\text { X-ray positive } \\
N=80\end{array}$ & $\begin{array}{l}\text { X-ray negative } \\
N=301\end{array}$ \\
\hline Age mean [range] & $72[60-88]$ & $70[59-94]$ & $72[60-86]$ & $70[59-94]$ \\
\hline Height mean [range] & $161[145-178]$ & $163[137-185]$ & $163[148-180]$ & $163[146-185]$ \\
\hline Weight mean [range] & $65[41-93]$ & $71[46-120]$ & $71[48-120]$ & $71[46-119]$ \\
\hline Race (Caucasian/ oriental/other) & $99.5 / 0.5 / 0$ & $98.8 / 0.7 / 0.5$ & $100 / 0 / 0$ & $99.0 / 0.7 / 0.3$ \\
\hline Fracture after age of 50 years $^{\mathrm{a}}$ & $73 \%$ & $69 \%$ & $78 \%$ & $68 \%$ \\
\hline Known existing vertebral fracture & $10 \%$ & $7 \%$ & $24 \%$ & $2 \%$ \\
\hline Low body weight $(<67 \mathrm{~kg})$ & $61 \%$ & $40 \%$ & $38 \%$ & $42 \%$ \\
\hline Low body weight $(<60 \mathrm{~kg})$ & $39 \%$ & $20 \%$ & $25 \%$ & $19 \%$ \\
\hline Current serious immobilization ${ }^{\mathrm{b}}$ & $16 \%$ & $15 \%$ & $13 \%$ & $15 \%$ \\
\hline $\begin{array}{l}\text { Positive familial history for fragility fractures } \\
\text { (particularly hip fracture in mother) }^{\mathrm{a}}\end{array}$ & $2 \%$ & $2 \%$ & $0 \%$ & $2 \%$ \\
\hline Early menopause (before age 45 ) & $23 \%$ & $34 \%$ & $23 \%$ & $34 \%$ \\
\hline $\begin{array}{l}\text { Current use of corticosteroid } \geq 3 \text { months } \\
(<7.5 \mathrm{mg} \text { and } \geq 2.5 \mathrm{mg} \text { prednisone (equivalent) daily) }\end{array}$ & $26 \%$ & $33 \%$ & $23 \%$ & $37 \%$ \\
\hline $\begin{array}{l}\text { Current use of corticosteroids } \geq 3 \text { months } \\
\text { ( } \geq 7.5 \mathrm{mg} \text { prednisone (equivalent) daily) }\end{array}$ & $2 \%$ & $2 \%$ & $3 \%$ & $2 \%$ \\
\hline
\end{tabular}

DXA positive $=T$-score $<-2.5$; DXA negative $=T$-score $\geq-2.5 ; \mathrm{X}$-ray positive $=$ vertebral fracture present; X-ray negative $=$ no vertebral fracture present.

${ }^{\text {a }}$ Rating based upon clinical judgment

${ }^{\mathrm{b}}$ Not walking for $\geq 4$ weeks in the last year

times, respectively, when information regarding spine fractures is considered [13]. Even when corrected for $\mathrm{BMD}$, prevalent vertebral fractures increase the risk of future fracture up to fivefold $[14,15]$. Therefore, assessment of vertebral fracture status, in addition to BMD, provides practical and relevant clinical information to aid in predicting fracture risk in postmenopausal women and in the selection of treatment. Since prevalent fractures in nonosteoporotic women have a very high predictive value for future fractures, it can safely be assumed that treatment of women with risk factors and prevalent vertebral fractures but non-osteoporotic BMD-scores will be highly cost effective.

Prior fractures that can be broadly considered as indicative of structural failure of the skeleton, increase significantly the risk of new fractures, and are often included in case-finding algorithms. Information about clinical fractures is easily obtained from the history of the patients. However, the most common and typical osteoporotic fractures, these of the vertebrae, are mainly asymptomatic. Yet, radiologically diagnosed vertebral deformities are associated with deterioration of certain aspects of the quality of life of the patients and numerous studies, confirmed by meta-analysis, have shown them to be strong, independent determinants of new osteoporotic fractures at several skeletal sites, including the hip [13, 16, 17]. Despite these and the efficacy of antiosteoporotic medications in patients with vertebral deformities, current case-finding strategies do not include spine radiographs in the selection of patients for treatment. Moreover, prospective evaluation of such strategies in general practice is scarce. The use of case-finding solely in order to select patients for BMD measurement with DXA will therefore still miss many patients at high risk for fractures. We found vertebral fractures on spine radiographs in $21 \%$ of the postmenopausal women with a positive risk profile for osteoporosis but who did not fulfill the WHO criteria for osteoporosis. This confirms the poor sensitivity of BMD measurements in identifying women requiring treatment.

In this prospective study, $30 \%$ of women with established clinical factors for fractures had osteoporosis. The addition, however, of spine radiographs in the evaluation of women with BMD $T$-scores $\geq-2.5$ helped to identify, in addition, a substantial number of women in whom treatment is indicated. Remarkably, the presence of vertebral deformities was already known in about $25 \%$ of these women but no action had been taken by their general practitioners. While this finding underscores the lack of specific symptoms in women with vertebral deformities, it illustrates also the attitude of physicians towards their presence despite their clinical importance [18]. Therefore, our results obtained in women at risk for osteoporotic fractures, are in agreement with previous studies that have examined the overall prevalence of vertebral fractures in cohorts of men and women. They differ, however, from previously reported studies in that we have prospectively selected women with clinical risk factors for fractures and we subsequently characterized those most likely to benefit from an intervention according to a step-wise protocol. The described, easy to apply in clinical practice, approach 
performs better than currently used algorithms in selecting individuals for treatment. The additional contribution of the diagnosed vertebral deformities to the 10-year fracture probability in this population of women remains to be estimated [19].

Nowadays, newer DXA machines with the capability to assess vertebral fractures on lateral spine images (morphometry X-rays absorptiometry; MXA) seem to be a good alternative for conventional spinal radiographs because of lower radiation exposure, and the possibility to perform both examinations at the same time [20]. However, MXA is not widely available and lateral spine images while allowing the diagnosis of vertebral fractures at levels where they are most common, i.e., the lumbar and mid and lower thoracic levels, their value is weaker at the upper thoracic levels. MXA appears less sensitive compared to lateral radiographs and has a tendency for overestimation of low grade vertebral fractures [21]. MXA, where available, might be considered as a screening tool [22] and lateral radiographs can be reserved for confirmation of suspected fractures that cannot be clearly visualized.

Our study has several limitations. We kept no record of women who were contacted by their GP based upon their case record but did not agree to undergo a DXA. Furthermore, 13\% of women with normal BMD refused to have additional spine radiographs. It is unclear what influence this may have had on the final outcome of our study. Finally, DXA and vertebral deformities results were captured in the case-record forms as dichotomous parameters (positive $=T$-score $<-2.5$ at the spine and/or at the hip or negative $=T$-score $\geq-2.5$ at both the spine and at the hip and present or absent vertebral deformities, respectively) which did not allow additional analyses in subgroups of women.

\section{Conclusion}

In this population of elderly women with clinical risk factors for osteoporosis and BMD T-score $\geq-2.5$, both at the spine and the hips, addition of spine radiographs in the overall risk assessment identified a substantial number of women at high risk who can benefit from therapeutic interventions. Spine radiographs, which are relatively cheap and readily available world-wide, should therefore be considered in these women and, in case of vertebral fractures, antiosteoporotic treatment should be considered.

Acknowledgments This study was supported and funded by F. Hoffmann-LaRoche, Ltd. and GlaxoSmithKline. The authors would like to acknowledge Nicole van de Griend, MSc, and Carien Gierveld, MSc, of GlaxoSmithKline for research assistance.

Conflicts of interest This study was supported and funded by Roche and GSK. Dr J.C. Netelenbos, Dr W.F. Lems, Dr P.P. Geusens,
Dr H.J. Verhaar, Dr A.J.M. Boermans, and Dr S.E. Papapoulos have no conflict of interest, including specific financial interest and relationships and affiliations relevant to the subject matter or materials discussed in the manuscript. Dr M.M. Boomsma is an employee of GSK. Dr P.G.H. Mulder has served as a consultant for GSK.

\section{References}

1. Anon (2002) America's bone health: the state of osteoporosis and low bone mass in our nation. National Osteoporosis Foundation, Washington (DC)

2. Anon (2004) Bone health and osteoporosis: a report of the surgeon general. Rockville (MD): US Department of Health and Human Services, Office of the Surgeon General. Available at http://www.surgeongeneral.gov/library/bonehealth/ [last accessed 7 June 2007]

3. RIVM osteoporosis fact sheath, available at http://www.rivm.nl/ vtv/object document/o1793n18373.html [last accessed at 7 June 2007]

4. Hofman A, Boerlage PA, Bots ML et al (1995) Prevalence of chronic diseases in the elderly; the ERGO study (Erasmus Rotterdam Health and the Elderly). Ned Tijdschr Geneeskd 139(39):1975-1978

5. Geusens PP, Lems WF, Verhaar HJ et al (2006) Review and evaluation of the Dutch guidelines for osteoporosis. J Eval Clin Pract 12(5):539-548

6. Kaptoge S, Armbrecht G, Felsenberg D et al (2006) Whom to treat? The contribution of veretebral X-rays to risk-based algorithms for fracture prediction: results from the European Prospective Osteoporosis Study. Osteoporos Int 17(9):1369-1381

7. CBO Guideline Osteoporosis; second revised guideline. Available at http://www.cbo.nl/product/richtlijnen/folder20021023121843/ osteoporose.pdf/view

8. Genant HK, Li J, Wu CY, Shepherd JA (2000) Vertebral fractures in osteoporosis: a new method for clinical assessment. J Clin Densitometry 3(3):281-290

9. Siris ES, Miller PD, Barrett-Connor E et al (2001) Identification and fracture outcomes of undiagnosed low bone mineral density in postmenopausal women. Results from the National Osteoporosis Risk Assessment. JAMA 286(22):2815-2822

10. Miller PD, Siris ES, Barrett-Connor E et al (2002) Prediction of fracture risk in postmenopausal white women with peripheral bone densitometry: evidence from the National Osteoporosis Risk Assessment. J Bone Miner Res 17(12):2222-2230

11. Schuit SC, van der Klift M, Weel AE et al (2004) Fracture incidence and association with bone mineral density in elderly men and women. The Rotterdam Study. Bone 34(1):195-202

12. Sornay-Rendu E, Munoz F, Garnero P Duboeuf F, Delmas PD (2005) Identification of Osteopenic Women at High Risk of Fracture: The OFELY Study. J Bone Miner Res 20(10):18131819

13. Siris ES, Genant HK, Laster AJ et al (2007) Enhanced prediction of fracture risk combining vertebral fracture status and BMD. Osteoporos Int 18(6):761-777

14. Black DM, Arden NK, Palermo L, Pearson J, Cummings SR (1999) Prevalent vertebral deformities predict hip fractures and new vertebral deformities but not wrist fractures. Study of Osteoporotic Fractures Research Group. J Bone Miner Res 14(5):821-828

15. Ismail AA, Cockerill W, Cooper $C$ et al (2001) Prevalent vertebral deformity predicts incident hip though not distal forearm fracture: results from the European Prospective Osteoporosis Study. Osteoporos Int 12(2):85-90

16. Klotzbuecher CM, Ross PD, Landsman PB, Abbott TA 3rd, Berger M (2000) Patients with prior fractures have an increased 
risk of future fractures: a summary of the literature and statistical synthesis. J Bone Miner Res 15(4):721-39

17. Kanis JA, Johnell O, De Laet C et al (2004) A meta-analysis of previous fracture and subsequent fracture risk. Bone 35(2):375-382

18. Lems WF (2007) Clinical relevance of vertebral fractures. Ann Rheum Dis 66(1):2-4

19. Kanis JA, Johnell O, Oden A et al (2008) FRAX and the assessment of fracture probability in men and women from the UK. Osteoporos Int 19(4):385-397
20. Khosla S, Melton LJ III (2007) Clinical practice. Osteopenia. N Engl J Med 356(22):2293-2300

21. Chapurlat RD, Duboeuf F, Marion-Audibert HO et al (2006) Effectiveness of instant vertebral assessment to detect prevalent vertebral fracture. Osteoporosis Int 17(8):1189-1195

22. Vosse D, Heijckmann C, Landewé R et al (2007) Comparing morphometric X-ray absorptiometry and radiography in defining vertebral wedge fractures in patients with ankylosing spondylitis. Rheumatology (Oxford) 46(11):1667-1671 